\title{
Degradation of Sucralose by Peroxidation Assisted with Ultraviolet Radiation and Photo-Fenton
}

\author{
Gabriela F. Ferreira, Milena G. Maniero, and José R. Guimarães
}

\begin{abstract}
Substances discharged intobodies of water must be studied due to possible risk of contamination and consequent damage to nature and human health.Sucralose is an artificial sweetener widely used to produce diet food and beverage. Most of this substance is expelled intact fromthe human body; therefore, its concentration in rivers and wastewaters is increasing worldwide. In this work, sucralose degradation was performed using advanced oxidation processes (AOPs): peroxidation assisted by ultraviolet radiation $\left(\mathrm{H}_{2} \mathrm{O}_{2} / \mathrm{UV}\right)$, Fenton's reagent $\left(\mathrm{Fe}(\mathrm{II}) / \mathrm{H}_{2} \mathrm{O}_{2} / \mathrm{H}^{+}\right)$, and photo-Fenton $\left(\mathrm{Fe}(\mathrm{II}) / \mathrm{H}_{2} \mathrm{O}_{2} / \mathbf{H}^{+} / \mathrm{UV}\right)$. Mineralization of the sweetener was measured usingtotal organic carbon (TOC). In addition, AOPs were applied to different water matrices, such as ultrapure, synthetic, and surface waters. Experiments were performed to evaluate the toxicity of the solution during the degradation processes.
\end{abstract}

Index Terms-AOPs, sweetener, toxicity, UV.

\section{INTRODUCTION}

Sucralose is a sweetener that is being used more frequently by the food industry. Sucralose was intended to be a substitute for aspartame, which may be carcinogenic. The sweetener was discovered in 1976 by researchers at Queen Elizabeth College, University of London, in a program in collaboration with UK sugar producer Tate \& Lyle, PLC. It is produced by a multi-step process withsucrose where three chlorine atoms replace three hydrogen-oxygen groups.It is sold under the trade name Splenda ${ }^{\mathbb{B}}$.Very little sucralose is metabolized by the body and it is excreted in its original form It is considered a stable anti-cariogeniccompound at cooking temperatures. This gives it a wide range of applications [1], [2].

Although there have been varioustoxicity tests and studies thatensure the safety of sucralose in food and beverages [3]-[5], there have been few studies of its fate and behavior after it's been excreted by the human body. Sucralose has beendetected in municipal wastewater and surface water in Europe. In the United States, its concentration has been increasing in recent years [6], [7]. Due to the presence of this substance in bodies of water, some scientists have turned their attention to its possible toxic effects on non-target species [8].

Since sucralose is found in drinking water, it is possible to suggest that in addition to the molecule itself, there may be

Manuscript received May 15, 2014; revised August 1, 2014. This work was supported by CNPq and FAPESP (2013/07817-2).

J. R. Guimarães and M. G. Maniero are with School of Civil Engineering, Architecture and Urban Design of UNICAMP, Campinas, SP 13083852 Brazil (e-mail: jorober@fec.unicamp.br,milenagm@fec.unicamp.br).

G. F. Ferreira is with Chemical Engineering School of UNICAMP, Campinas, SP 13083852 Brazil (e-mail: g119458@dac.unicamp.br). many others present in the environment:that is, Wastewater Treatment Plants (WWTP) are not completely efficient at removingsome recalcitrant compounds. Advanced oxidation processes (AOPs) may be a good option to degrade this artificial sweetener. AOPs are based on generation of hydroxyl radicals $(\cdot \mathrm{OH})$, which have ahigh reduction potential $(\sim 2.80 \mathrm{~V})$ [9], capable of causing mineralization of organic matter, i.e., turning it into carbon dioxide, water, and inorganic ions. The most common processes are peroxidation assisted by UV radiation $\left(\mathrm{H}_{2} \mathrm{O}_{2} / \mathrm{UV}\right)$, Fenton's reagent ( $\left.\mathrm{Fe}(\mathrm{II}) / \mathrm{H}_{2} \mathrm{O}_{2} / \mathrm{H}^{+}\right)$, and photo-Fenton ( $\mathrm{Fe}(\mathrm{II}) / \mathrm{H}_{2} \mathrm{O}_{2} / \mathrm{H}^{+} / \mathrm{UV}$ ) [10], [11]. Peroxidation assisted by ultraviolet radiation is a simple and efficient process for producing a large number of $\cdot \mathrm{OH}$ radicals; therefore, it is suitable for degradation of organic molecules. Photo-Fenton consists ofacombination of $\mathrm{Fe}(\mathrm{II})$ and hydrogen peroxide and application of UV radiation [12].

During AOPs, a common degradation pathway is the addition of a hydroxyl group to carbons of the molecule. Analyzing the structural formula of sucralose, shown in Fig. 1 , the potential reaction sites are where the three chlorine atoms are located [5].

In addition to studies confirming the safety of sucralose consumption, there have beenpapers that show that AOPs are viable options for sucralose degradation [13], [14]. However,intermediate products from its degradation can be toxic; so, toxicity assays can show how toxicthe byproducts formed are by inhibitingthe activity of a microorganism. The sucralose molecule has chlorine atoms, so itsdegradation could generate toxic intermediates, such as toxic chlorinated compounds. Therefore, in addition to degradation assays, bioassayscould be conducted to evaluate its toxicity. Studies with aerobic and anaerobic biological reactors have shown that these processes were not able to degrade the molecule [15].

The aim of this study was to evaluate the degradation of sucralose by $\mathrm{H}_{2} \mathrm{O}_{2} / \mathrm{UV}$, Fenton's reagent and photo-Fenton inultrapure water, a synthetic water matrix, and surface water.Acute toxicity tests using the bacteria $V$. fischeri were alsoperformed to predict possible environmental impacts.

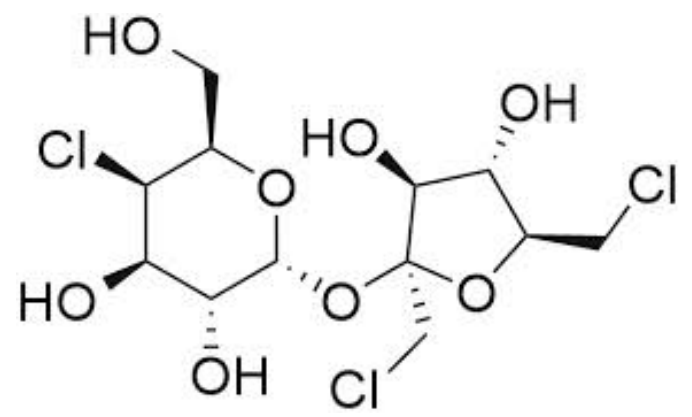

Fig. 1. The structural formula of sucralose. 


\section{MATERIALS AND Methods}

\section{A. Reagents}

Sucralose $(\geq 98 \%$ ) was purchased from Sigma Aldrich (São Paulo, Brazil), hydrogen peroxide $(30 \% \mathrm{~m} / \mathrm{m})$ from Synth (Diadema, Brazil), and ferrous sulphate heptahydratefrom Synth (Diadema, Brazil).Ultrapure water used for the preparation of the solutions was obtained using a Milli-Q system (Millipore). The synthetic water was prepared with sodium bicarbonate from 'Cinetica Quimica Ltda' (São Paulo, Brazil), magnesium sulfatefrom Vetec (Rio de Janeiro, Brazil), and calcium sulfate and potassium chloride from Synth (Diadema, Brazil). Concentration are shown onTable I. Surface water was collected from 'Fazenda Rio das Pedras' lake near the city of Campinas in Brazil.

Hardness, alkalinity, and $\mathrm{pH}$ were measured for the synthetic water matrix; hardness, alkalinity, $\mathrm{pH}$, conductivity, color, and turbidity were measured for surface water, as shown onTable II.

\section{B. Experimental Conditions}

The concentration of sucralose $\left(\mathrm{C}_{12} \mathrm{H}_{19} \mathrm{O}_{8} \mathrm{Cl}_{3}\right)$ in aqueous solutionswas approximately $55 \mu \mathrm{g} / \mathrm{cm}^{3}$, corresponding to 20 $\mu \mathrm{g} / \mathrm{cm}^{3}$ of total organic carbon (TOC). In the peroxidation $\left(\mathrm{H}_{2} \mathrm{O}_{2}\right)$ and $\mathrm{H}_{2} \mathrm{O}_{2} / \mathrm{UV}$ processes, hydrogen peroxide concentrations were based on the stoichiometry presented in (1). The reagents were used at $\mathrm{C}_{12} \mathrm{H}_{19} \mathrm{O}_{8} \mathrm{Cl}_{3}: \mathrm{H}_{2} \mathrm{O}_{2}$ molar ratios of $1: 24$, or $3.3 \mu \mathrm{mol} / \mathrm{cm}^{3} \mathrm{H}_{2} \mathrm{O}_{2} ; 1: 48 \mathrm{C}_{12} \mathrm{H}_{19} \mathrm{O}_{8} \mathrm{Cl}_{3}: \mathrm{H}_{2} \mathrm{O}_{2}$, or $6.6 \mu \mathrm{mol} / \mathrm{cm}^{3} \mathrm{H}_{2} \mathrm{O}_{2}$; and $1: 96 \mathrm{C}_{12} \mathrm{H}_{19} \mathrm{O}_{8} \mathrm{Cl}_{3}: \mathrm{H}_{2} \mathrm{O}_{2}$, or 13.2 $\mu \mathrm{mol} / \mathrm{cm}^{3} \mathrm{H}_{2} \mathrm{O}_{2}$. The $1: 600 \mathrm{C}_{12} \mathrm{H}_{19} \mathrm{O}_{8} \mathrm{Cl}_{3}: \mathrm{H}_{2} \mathrm{O}_{2}$ molar ratio was also used in the $\mathrm{H}_{2} \mathrm{O}_{2} / \mathrm{UV}$ process to evaluate if the excessive increase in $\mathrm{H}_{2} \mathrm{O}_{2}$ concentration significantly alters the results.

$$
\mathrm{C}_{12} \mathrm{H}_{19} \mathrm{O}_{8} \mathrm{Cl}_{3}+24 \mathrm{H}_{2} \mathrm{O}_{2} \rightleftharpoons 3 \mathrm{HCl}+32 \mathrm{H}_{2} \mathrm{O}+12 \mathrm{CO}_{2}
$$

For Fenton and photo-Fenton processes, Fe(II) concentrations of 1.1, 2.2 and $4.4 \mu \mathrm{mol} / \mathrm{cm}^{3}$ were used. These $\mathrm{Fe}(\mathrm{II})$ concentrations were tested for molar ratios $\mathrm{C}_{12} \mathrm{H}_{19} \mathrm{O}_{8} \mathrm{Cl}_{3}: \mathrm{H}_{2} \mathrm{O}_{2}$ of 1:24 and 1:96. The $\mathrm{Fe}(\mathrm{II})$ ions were obtained from $\mathrm{FeSO}_{4} \cdot 7 \mathrm{H}_{2} \mathrm{O}$. The tests proposed were all performed in duplicate and the graphs presented in Results and Discussion show the error bars calculated using the values' standard deviation.

\begin{tabular}{cc}
\multicolumn{2}{c}{ TABLE I: SYNTHETIC WATER COMPOSITION } \\
\hline \hline Substance & Concentration $\left(\mu \mathrm{g} / \mathrm{cm}^{3}\right)$ \\
\hline $\mathrm{NaHCO}_{3}$ & 12.0 \\
$\mathrm{CaSO}_{4}$ & 6.0 \\
$\mathrm{MgSO}_{4}$ & 7.5 \\
$\mathrm{KCl}$ & 0.5 \\
\hline \hline
\end{tabular}

TABLE II: SYNTHETIC WATER MATRIX AND SURFACE WATER PROPERTIES

\begin{tabular}{ccc}
\hline Parameter & $\begin{array}{c}\text { Synthetic Water } \\
\text { Matrix }\end{array}$ & Surface Water \\
\hline Hardness, in $\mu \mathrm{g} / \mathrm{cm}^{3} \mathrm{CaCO}_{3}$ & 11.0 & 22.0 \\
Alkalinity, in $\mu \mathrm{g} / \mathrm{cm}^{3} \mathrm{CaCO}_{3}$ & 11.6 & 38.4 \\
$\mathrm{pH}$ & 7.17 & 6.59 \\
Conductivity, in $\mu \mathrm{S} / \mathrm{cm}$ & - & 65.4 \\
Color, in Pt-Co & - & Real: 30 \\
Turbidity, in TU & - & Apparent: 49 \\
\hline \hline
\end{tabular}

\section{Experimental System}

The laboratory setup consisted of a cylindrical photochemical reactor made of borosilicate glass $(4 \mathrm{~cm}$ inner diameter and $42.5 \mathrm{~cm}$ length) with a germicidal lamp $(2.5 \mathrm{~cm}$ inner diameter, $15 \mathrm{~W}$, and $\lambda_{\max }=254 \mathrm{~nm}$ ) inserted in the center; the lamp was in direct contact with the solution. The working volume of the reactor was about $300 \mathrm{~cm}^{3}$ and a magnetic stirrer was used to homogenize the solutions. As shown in Fig. 2, the system was operated in batches with recirculation of the solution.

\section{Analytical Methods}

Sucralose degradation was evaluated by a TOC analyzer (Shimadzu TOC 5000A, Sao Paulo, Brazil), by monitoring the content of total organic carbon. The spectrum of the substance was not obtained because it does not absorb in the $\mathrm{UV} / \mathrm{visible}$ range because it does not have a chromophore group [16].

The concentration of residual hydrogen peroxide was also monitored throughout the reaction time. This control is based on an reaction between the substance and a metavanadate ion $\left(\mathrm{VO}_{3}{ }^{-}\right)$, which is yellow. Peroxovanadium cation $\left(\mathrm{VO}_{2}{ }^{3+}\right)$ is formed in the presence of $\mathrm{H}_{2} \mathrm{O}_{2}$, so the solution turns red and has a maximum absorbance at the wavelength of $450 \mathrm{~nm}$. Maximum absorbance was measured by a spectrophotometer $(\mathrm{HACH}, \mathrm{DR} 4000)$. The oxidation-reduction reaction is shown in (2) [12], [17].

$$
\mathrm{VO}_{3}^{-}+4 \mathrm{H}^{+} \rightarrow \mathrm{VO}_{2}^{3+}+3 \mathrm{H}_{2} \mathrm{O}
$$

\section{E. Toxicity Assays}

The toxicity assays were carried out based on standard procedure L5.227 from CETESB [18] using a Microtox Model 500 Analyzer (Strategic Diagnostics Inc., Newark, Delaware, USA). The toxicity of the initial solution and solutions submitted to $\mathrm{H}_{2} \mathrm{O}_{2} / \mathrm{UV}$ process (1:24 and 1:96 sucralose:hydrogen peroxide molar ratios) were evaluated, monitoring the changes between initial $V$. fischeriluminescence and its luminescence after 1800 seconds of exposure.

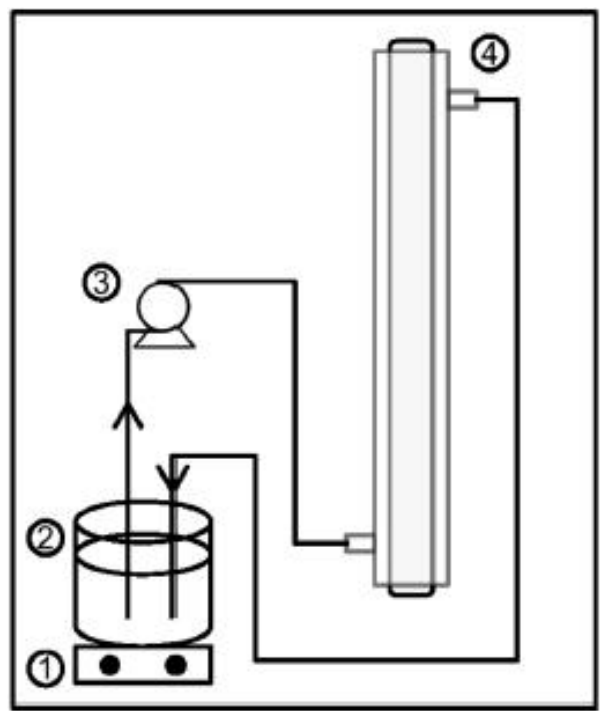

Fig. 2. Experiment setup: (1) magnetic stirrer, (2) vessel, (3) peristaltic pump, and (4) photochemical reactor. 
Luminescence was measured directly from aliquots taken after $0,900,1800,2700,3600,5400,7200$, and 9000 sof testing. Also, luminescence of theaqueous $\mathrm{H}_{2} \mathrm{O}_{2}$ solutions (concentrations of $2,3.3,6,8,10$, and $13.2 \mu \mathrm{mol} / \mathrm{cm}^{3}$ ) wasevaluated to find out iftoxicity results were from sucralose degradationor the oxidant agent. The results of bacteria inhibition were calculated following the established protocol of the Microtox software (SDI MicrotoxOmni 4.0) (Strategic Diagnostics Inc, Newark, Delaware, USA).

\section{RESUlTS AND DISCUSSION}

\section{A. Degradation in Ultrapure Water}

\section{1) Experimental parameters}

Temperature and $\mathrm{pH}$ were monitored during the experiments, although the data is not presented here. The temperature remained the same, around $26^{\circ} \mathrm{C}$, in degradation using the peroxidation and Fenton processes, and increased smoothly in UV mediated processes. The $\mathrm{pH}$ values of the initial solution were neutral in general, around 6.8. For peroxidation and photolysis processes, $\mathrm{pH}$ remained nearlyconstant during testing; forFenton and photo-Fenton processes, it was around 2.5; and for $\mathrm{H}_{2} \mathrm{O}_{2} / \mathrm{UV}$, it was around 3.3. The recommended $\mathrm{pH}$ range ofFenton and photo-Fenton is $2.5-3.0$, so the $\mathrm{pH}$ value didnot need to be corrected with an acid or base solution.

The aliquots that underwentFenton and photo-Fenton had to be centrifuged to remove the ironbefore the TOC analysis, because this compound could clog the equipment pathway and damage it. An Excelsa 2 Model 205 N Centrifuge from Fanem (Sao Paulo, Brazil) was used for this purpose; it was runfor 300 secondsat $2000 \mathrm{rpm}$.

\section{2) Degradation by UV, H2O2, and H2O2/UV processes}

In $\mathrm{UV}$ and $\mathrm{H}_{2} \mathrm{O}_{2}$ processes, TOC value did not vary throughout the time of the experiment ( 0 to $7200 \mathrm{~s})$. This shows that neither photolysis nor peroxidation processes were able to mineralize the molecule (see Fig. 3).

The mechanism of the $\mathrm{H}_{2} \mathrm{O}_{2} / \mathrm{UV}$ reaction consists of photolysis of the $\mathrm{H}_{2} \mathrm{O}_{2}$ molecule into two hydroxyl radicals, as shown in (3).

$$
\mathrm{H}_{2} \mathrm{O}_{2} \stackrel{\mathrm{h} v}{\rightarrow} 2 \cdot \mathrm{OH}
$$

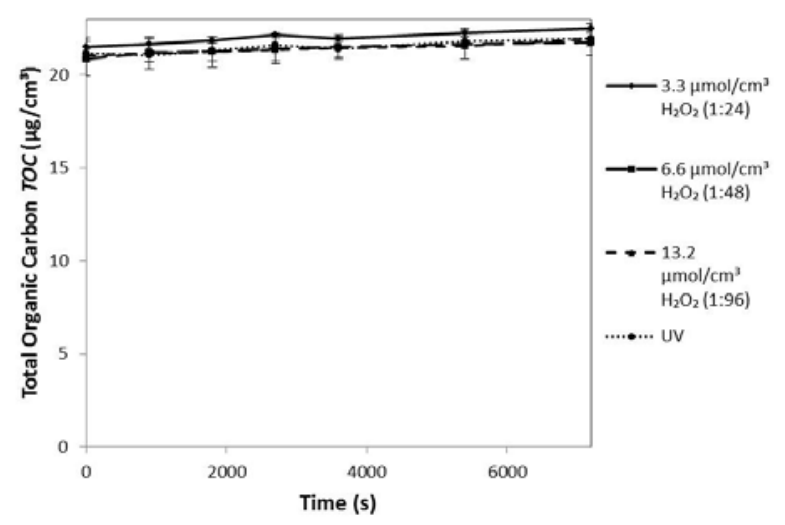

Fig. 3. Degradation of sucralose by $\mathrm{H}_{2} \mathrm{O}_{2}$ and UV processes.

In the $\mathrm{H}_{2} \mathrm{O}_{2} / \mathrm{UV}$ process, degradation tests lasted two and a half hours. As shown in Fig. 4, 88.6\% mineralization of the molecule was obtained usinga sucralose:hydrogen peroxide molar ratio of 1: 96. The mineralization efficiencyachieved were very close; it did not increase with a significant increase of hydrogen peroxide concentration. It is important to highlight that with excess peroxide and high concentrations of ${ }^{\circ} \mathrm{OH}$, competitive reactions occur thatslow the degradation rate, as shown in (4)-(6). For this reason, optimal $\mathrm{H}_{2} \mathrm{O}_{2}$ concentrations has to be determined to avoid oxidant excess that can impair the reaction and reduce its efficiency [19], [20].

$$
\begin{gathered}
\cdot \mathrm{OH}+\cdot \mathrm{OH} \rightarrow \mathrm{H}_{2} \mathrm{O}_{2} \\
\cdot \mathrm{OH}+\mathrm{O}_{2} \mathrm{H} \rightarrow \mathrm{H}_{2} \mathrm{O}+\mathrm{O}_{2} \\
\cdot \mathrm{OH}+\mathrm{H}_{2} \mathrm{O}_{2} \rightarrow{ }^{\circ} \mathrm{O}_{2} \mathrm{H}+\mathrm{H}_{2} \mathrm{O}
\end{gathered}
$$

\section{3) Degradation by fenton and photo-fenton processes}

The reaction of Fenton's reagent is shown in (7). The photo-Fenton process consists of Fenton's reagent combined with ultraviolet radiation. It significantly accelerates the degradation of organic compounds due to the regeneration of $\mathrm{Fe}(\mathrm{II})$ ions shown in (8).

$$
\begin{gathered}
\mathrm{Fe}(\mathrm{II})+\mathrm{H}_{2} \mathrm{O}_{2} \stackrel{\mathrm{H}^{+}}{\rightarrow} \mathrm{Fe}(\mathrm{III})+\mathrm{OH}^{-}+\cdot \mathrm{OH} \\
{[\mathrm{Fe}(\mathrm{OH})]^{2+} \stackrel{\mathrm{h} \nu}{\rightarrow} \mathrm{Fe}(\mathrm{II})+{ }^{\bullet} \mathrm{OH}}
\end{gathered}
$$

For Fenton's reagent, mineralization of the compound was observed in the first 1200seconds of testing, as shown in Fig. 5. After this time, TOC concentration stabilizes, indicating that the compound didnot undergo further degradation. This behavior is typical when using Fenton's reagent because the rate of the process decreases as the catalyst $\mathrm{Fe}(\mathrm{II})$ is consumed. Moreover, stable Fe(III) complexes can be formed. When the concentration of iron is too small, the degradation efficiency of sucralose is very low, even in the presence of oxidant $\left(\mathrm{H}_{2} \mathrm{O}_{2}\right)$. The oxidant is unable to react with the sweetener, as previously discussed.

The results obtained using 1: 96 sucralose:hydrogen peroxide concentration had superior degradation than the 1 : 24 sucralose:hydrogen peroxide molar ratio; the degradation efficiency of the 1: 96 concentration was $46.4 \%$.

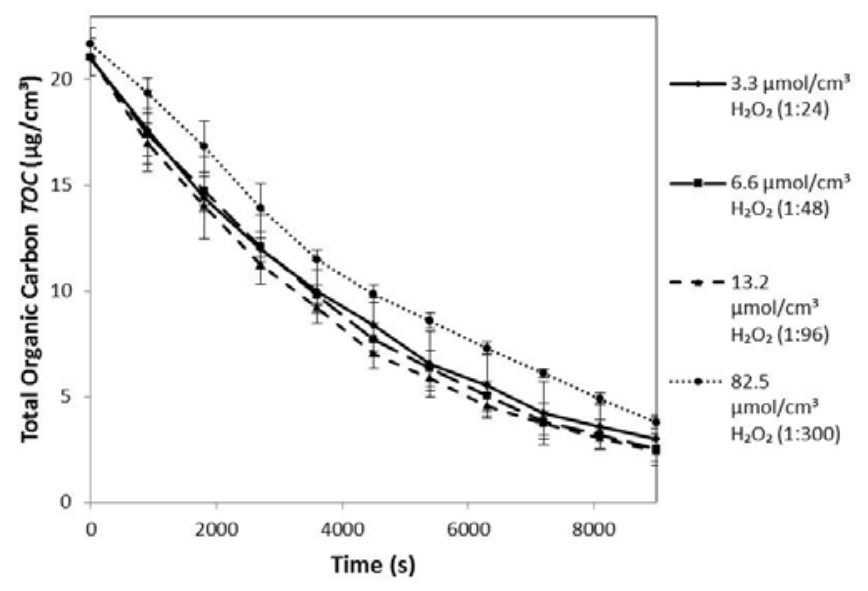

Fig. 4. Degradation of sucralose by the $\mathrm{H}_{2} \mathrm{O}_{2} / \mathrm{UV}$ process. 
Thus, efficiency increased as $\mathrm{H}_{2} \mathrm{O}_{2}$ concentration increased. However, when the $\mathrm{Fe}(\mathrm{II})$ concentration rose to $4.4 \mu \mathrm{mol} / \mathrm{cm}^{3}$, the reaction was impaired, decreasing its efficiency. This may have beendue to scavenging of hydroxyl radicals by excess $\mathrm{Fe}(\mathrm{II})$, as shown in (9).

Finally, the results obtained with the photo-Fenton process Fig. 6 had higher degradationpercentages in shorter periods of time. For two hour assays (7200 s), a maximum sweetener mineralization of $98.7 \%$ was obtained for the sucralose:hydrogen peroxide molar ratio of 1:96 and $\mathrm{Fe}(\mathrm{II})$ concentration of $2.2 \mu \mathrm{mol} / \mathrm{cm}^{3}$. This means that the compound was almost completely mineralized and there were no more organic molecules present in the solution. In most cases, keeping $\mathrm{Fe}$ (II) concentration constant and increasing $\mathrm{H}_{2} \mathrm{O}_{2}$ concentration increased degradation. In general, keeping $\mathrm{H}_{2} \mathrm{O}_{2}$ concentration constant and increasing $\mathrm{Fe}$ (II) concentrationdecreased degradation. This is because in excess, iron ions act as hydroxyl radicals scavengers, as discussed above andshown in (9) [21].

$$
\mathrm{Fe}(\mathrm{II})+\bullet \mathrm{OH} \rightarrow \mathrm{Fe}(\mathrm{III})+\mathrm{OH}^{-}
$$

When all of the processes studied in this work are analyzed, it can be seen that the advanced oxidation processes have the highest percentages of mineralization and are therefore best suited to the purpose. When comparing the

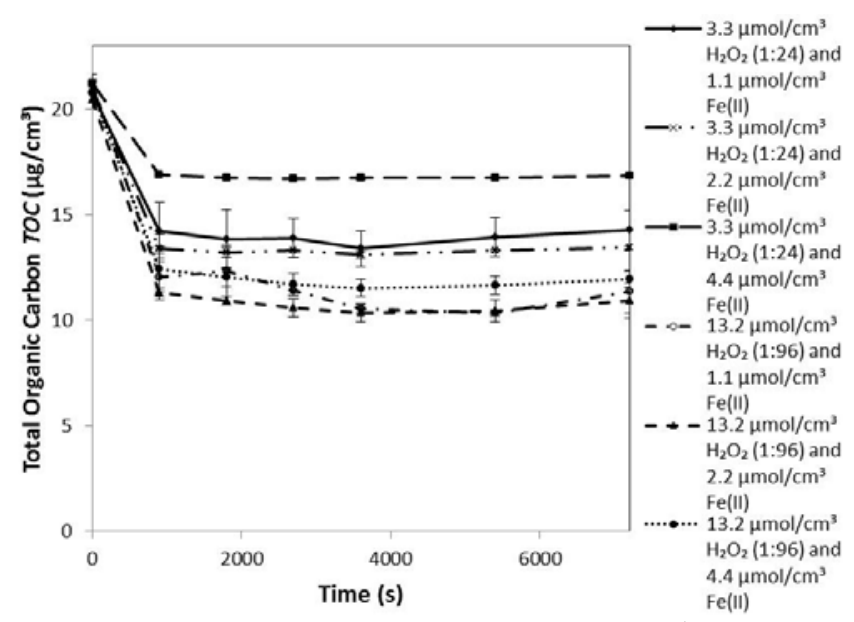

Fig. 5. Degradation of sucralose by the $\mathrm{Fe}(\mathrm{II}) / \mathrm{H}_{2} \mathrm{O}_{2} / \mathrm{H}^{+}$process.

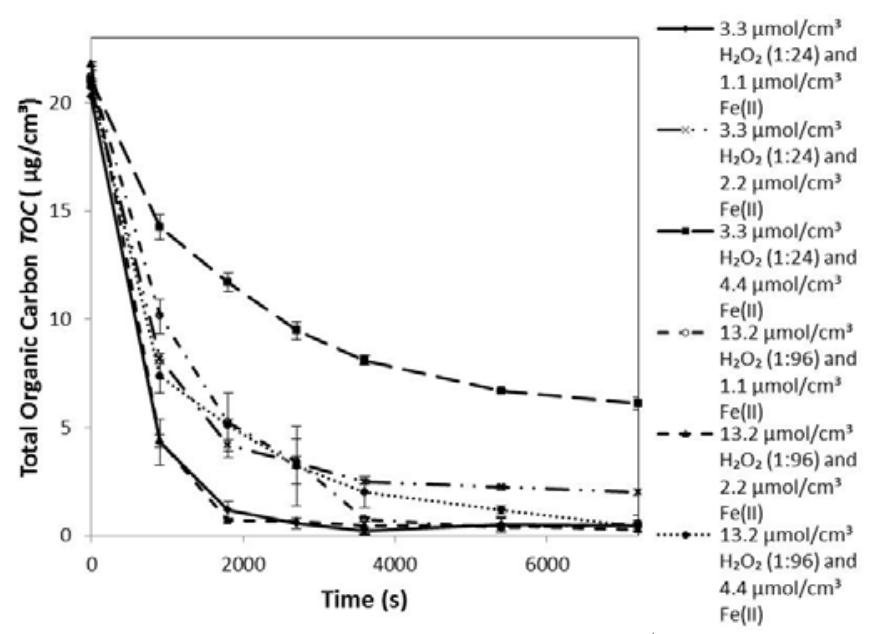

Fig. 6. Degradation of sucralose by the $\mathrm{Fe}(\mathrm{II}) / \mathrm{H}_{2} \mathrm{O}_{2} / \mathrm{H}^{+} / \mathrm{UV}$ process.

$\mathrm{H}_{2} \mathrm{O}_{2} / \mathrm{UV}$ and photo-Fenton processes, the
photo-Fentonensures higher efficiency in a shorter period of time; however, it has some disadvantages: the addition of reagents to adjust $\mathrm{pH}$ and the generation of sludge. The Fenton's reagent process had significant mineralization during the beginning of testing, but there efficiency leveled as the limiting reagent $\mathrm{Fe}(\mathrm{II})$ was consumed. The photo-Fenton process offers a solution to this problem,since $\mathrm{UV}$ radiation regenerates $\mathrm{Fe}(\mathrm{II})$ ions. It starts a cycle and makes the method more efficient. The photolytic and peroxidation processes were not able to degrade the sweetener.

\section{4) Residual peroxide}

Residual peroxide was measured for AOPs $\left(\mathrm{H}_{2} \mathrm{O}_{2} / \mathrm{UV}\right.$, Fenton, and photo-Fenton) andthe chemical process of peroxidation. For peroxidation, $\mathrm{H}_{2} \mathrm{O}_{2}$ concentration remained nearly constant from the beginning to the end of the test; that is, it was not consumed throughout the time of the reaction, indicating that there really was no reaction between the sweetener and the oxidant. For $\mathrm{H}_{2} \mathrm{O}_{2} / \mathrm{UV}$, the decrease of peroxide concentration was almost proportional with time; the minimum concentration measured in 9000 seconds was 0.14 $\mu \mathrm{mol} / \mathrm{cm}^{3}$. For photo-Fenton, concentration decreased exponentially, and at the end of the experiment, the residual peroxide concentration was below the detection limit $(0.0245$ $\left.\mu \mathrm{mol} / \mathrm{cm}^{3}\right)$. Finally, for Fenton, the oxidant concentration decreased in inverse proportion to $\mathrm{Fe}(\mathrm{II})$ concentration; that is, the lowest concentration of $\mathrm{Fe}(\mathrm{II})$ corresponded to the highest concentration of remaining $\mathrm{H}_{2} \mathrm{O}_{2}$ because less $\mathrm{Fe}$ (II) reacted with the oxidant to produce hydroxyl radicals.

\section{5) Chemical reaction kinetic}

The order of the chemical reactions was evaluated to determinethe kinetic parameters. For degradation using $\mathrm{H}_{2} \mathrm{O}_{2} / \mathrm{UV}$, the reaction was of the first order, with areaction rate constant of $2.223 \times 10^{-4} \mathrm{~s}^{-1}$ for a sucralose:hydrogen peroxide concentration of $1: 24$; the reaction rate constant was $2.454 \times 10^{-4} \mathrm{~s}^{-1}$ for a sucralose:hydrogen peroxide concentration of 1:48; the reaction rate constant was $2.399 \times$ $10^{-4} \mathrm{~s}^{-1}$ for a sucralose:hydrogen peroxide concentration of 1:96; andthe reaction rate constant was $2.016 \times 10^{-4} \mathrm{~s}^{-1}$ for a sucralose:hydrogen peroxide concentration of 1:300. Fig. 4 shows that in general, total organic concentration does not vary significantly with hydrogen peroxide concentration. For the other processes, it was not possible to determine the reaction order because the results were not consistent; the model must follow an unconventional reaction order.

\section{B. Ultrapure Water, Synthetic Matrix, and Surfacewater}

The two most effective AOPs were used to degrade sucralose in different aqueous matrices. $\mathrm{H}_{2} \mathrm{O}_{2} / \mathrm{UV}$ and photo-Fenton processes were compared using a 1:24 molar ratio sucralose:hydrogen peroxide and $\mathrm{Fe}(\mathrm{II})$ concentration of $1.1 \mu \mathrm{mol} / \mathrm{cm}^{3}$.

Fig. 7 shows that the degradation behavior was almost the same for ultrapure and synthetic water.This means that salts do not interfere withthe efficiency of sucralose degradation. There is a notable difference between these two matrices and surface water because it contains different dissolved organic molecules as well as other substances. Although the initial concentration of sucralose was $55 \mu \mathrm{g} / \mathrm{cm}^{3}$ in all aqueous matrices, TOC concentration was higher for 
surface water, as was expected. Nevertheless, at the end of the experimentmineralization of surface water was very similar to that ofpure water and the synthetic matrix. This consolidates the idea that $\mathrm{H}_{2} \mathrm{O}_{2} / \mathrm{UVis}$ a good optionfor degrading this sweetener and other organic compounds that are not removed by conventional wastewater treatment.

Photo-Fenton degradation with surface water had a very similar curve toultrapurewater and synthetic matrix water, as shown in Fig. 8. The outcome shows that this method is also effective in order to degrade the sweetener, even in real water sources.

Comparing both processes using surface water, it is clear that photo-Fenton is more effective, in a shorter period of time, on degrading sucralose, as well as other organic substances present in surface water. The final mineralization efficiency was $89.6 \%$ for $\mathrm{H}_{2} \mathrm{O}_{2} / \mathrm{UV}$ in a two-and-a-half-hour reaction; final mineralization efficiency was $90.7 \%$ for photo-Fenton in a two-hour reaction. If only the first hour of the experiments is considered, the degradation efficiency was $42.1 \%$ for $\mathrm{H}_{2} \mathrm{O}_{2} / \mathrm{UV}$ versus $90.5 \%$ for photo-Fenton. Clearly reaction time, degradation effectiveness, reagent availability, byproduct formation, and other factors have to be considered in order to select the best process.

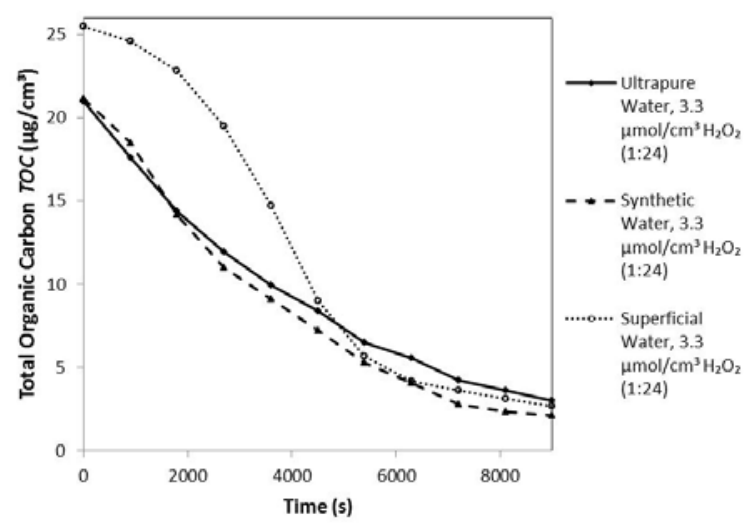

Fig. 7. Degradation of sucralose by the $\mathrm{H}_{2} \mathrm{O}_{2} / \mathrm{UV}$ process in different aqueous matrices.

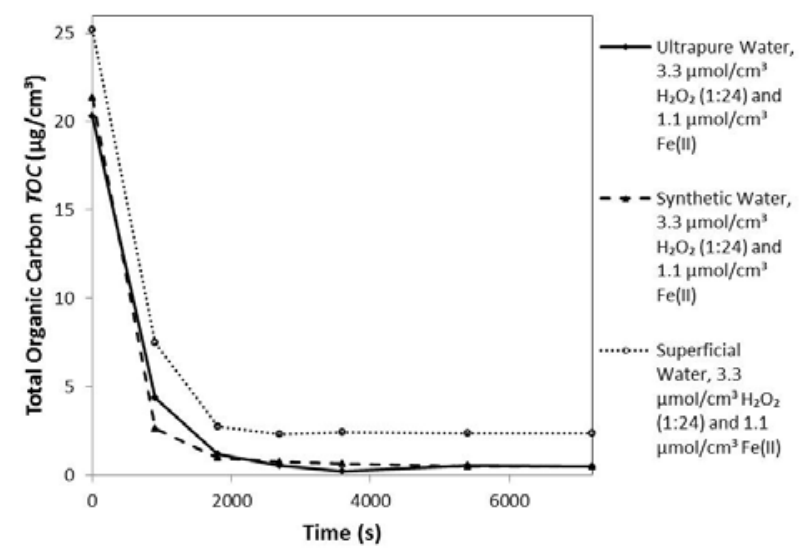

Fig. 8. Degradation of sucralose by $\mathrm{Fe}(\mathrm{II}) / \mathrm{H}_{2} \mathrm{O}_{2} / \mathrm{H}^{+} / \mathrm{UV}$ processes in different aqueous matrices.

\section{Toxicity Assays}

Fig. 9 shows theresults of bacteria inhibitions when using a 1:24 sucralose:hydrogen peroxide molar ratio; Fig.10 shows the results of bacteria inhibitions when using a 1:96 sucralose:hydrogen peroxide molar ratio.
Solutions of hydrogen peroxide ( 0 to $13.2 \mu \mathrm{mol} / \mathrm{cm}^{3}$ ) were also analyzed using Microtox ${ }^{\circledR}$. Bacteria inhibition wasdirectly proportional to $\mathrm{H}_{2} \mathrm{O}_{2}$ concentration(linear correlation coefficient of 0.9735 ). This shows thatat high concentration, this reagent is toxic. Toxicity results were accurate when $\mathrm{H}_{2} \mathrm{O}_{2}$ concentration was lower. The sweetener solution $\left(55 \mu \mathrm{g} / \mathrm{cm}^{3}\right.$ sucralose in ultrapure water) did not inhibit bacteria growth; that is, sucralose is not toxic toVibrio fischeri. Due to the toxicity of hydrogen peroxide, the residual oxidant concentration was also plotted in Fig. 9 and Fig. 10.

Inhibition behavior was similar to the residual hydrogen peroxide curve Fig. 9. As pointed out before, toxicity (inhibition percentage) was proportional to $\mathrm{H}_{2} \mathrm{O}_{2}$ concentration; therefore, it is plausible that the toxicity was due to $\mathrm{H}_{2} \mathrm{O}_{2}$ reagent and that toxic byproducts were not formed.

For the highest $\mathrm{H}_{2} \mathrm{O}_{2}$ concentration (1:96 sucralose:hydrogen peroxide molar ratio) (Fig. 10), toxiccompounds were formed during the degradation process.

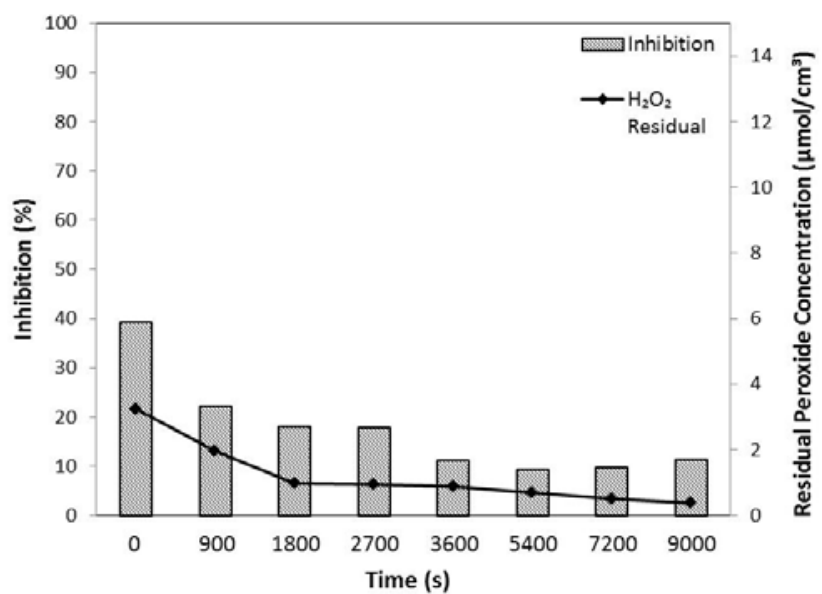

Fig. 9. Toxicity and residual hydrogen peroxideduring sucralose degradation by $\mathrm{H}_{2} \mathrm{O}_{2} / \mathrm{UV}$ (1:24 sucralose:hydrogen peroxide molar ratio).

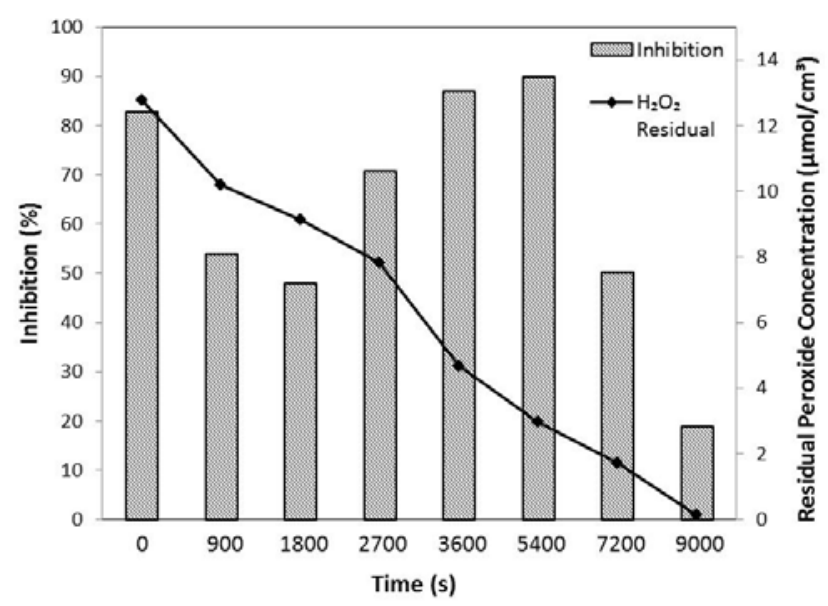

Fig. 10. Toxicity and residual hydrogen peroxide during sucralose degradation by $\mathrm{H}_{2} \mathrm{O}_{2} / \mathrm{UV}$ (1:96 sucralose:hydrogen peroxide molar ratio).

In the first 1800 seconds of testing, Vibrio fischeriinhibitioncould be caused only by $\mathrm{H}_{2} \mathrm{O}_{2}$, as there was a correlation between inhibition and residual oxidant concentration. However, from 2700 to 5400 secondsof 
testing, toxicity increased. This means that toxic byproductswere formed, since $\mathrm{H}_{2} \mathrm{O}_{2}$ concentration continued to decrease. After two hours of testing (7200 s), toxicity begins to decrease again, with the lowest toxicity result taking place at the end of the experiment $(9000 \mathrm{~s})$.

Even though the TOC profile was approximately the same for the two sucralose:hydrogen peroxide molar ratios (1:24 and 1:96) shown in Fig. 4, the byproducts formed during the degradation processes were different, because for the 1:24 concentration there was no toxicity. Moreover, it is important to highlight that at the end of the experiment, the toxicity was less for the 1:24 sucralose: hydrogen peroxide molar ratio despite the residual oxidant concentration beingslightly higher.

The stoichiometricconcentrationof sucralose to hydrogen peroxide of 1:24 was the optimum condition, since the degradation efficiency was about the same, less reagent was necessary for sweetener degradation, and the intermediate molecules formed were not highly toxic.

\section{CONCLUSIONS}

Sucralose is a chemically and photolytically stable compound. It was not degraded using only UV radiation or $\mathrm{H}_{2} \mathrm{O}_{2}$ at the doses evaluated in the present work. Fenton's reagent was able to degrade the molecule for the first 1200 seconds of testing,but after this period of time, the TOCconcentration reached a plateauas iron ions were consumed. $\mathrm{H}_{2} \mathrm{O}_{2} / \mathrm{UV}$ and photo-Fentonwere the best processes for sucralose degradation and mineralization, but peroxidation assisted by UV radiation had a lowermineralization efficiency and a longer reaction time.

Comparing degradation in different water matrices, it can be concluded that there were no significant difference between ultrapure water and the synthetic watermatrix. Using surface water, the mineralization efficiency was slightly reduced due to the presence of organic compounds and other substances. The AOPs utilizedcan be used for sweetener degradation, especially those mediated by UV radiation.

Toxicity results showed that sucralose is not toxic, but intermediate compounds formed from its degradation could be. Bacteria inhibitiondecreased during the first 1800 seconds of testing and increased at 2700 seconds for the $1: 96$ sucralose:hydrogen peroxide molar ratio, because toxic byproducts were formed. For the1:24 sucralose:hydrogen peroxide molar ratio, the byproducts formed were not toxic; so, thisstoichiometric concentration is superior.

\section{ACKNOWLEDGMENTS}

The authors gratefully acknowledge CNPq and FAPESP for providing scholarships to G.F. Ferreira and M.G. Maniero (2013/07817-2).

\section{REFERENCES}

[1] R. Khan, M. Mathlouthi, and P. Reiser, Sucrose: Properties and Applications, Glasgow: Blackie Academic \& Professional - Chapman \& Hall, 1995, ch. 11.

[2] All about Sucralose. [Online]. Available: http://www.sucralose.org.

[3] V. L. Grotz and I. C. Munro, "An overview of the safety of sucralose," Regulatory Toxicology and Pharmacology, vol. 55, pp. 1-5, 2009.
[4] H. C. Grice and L. A. Goldsmith, "Sucralose - an overview of the toxicity data," Food and Chemical Toxicology, vol. 38, pp. S1-S6, 2000.

[5] L. A. Goldsmith, "Acute and subchronic toxicity of sucralose," Food and Chemical Toxicology, vol. 38, pp. S53-S69,2000.

[6] T. S. S. Neset, H. Singer, P. Longrée, H. P Bader, R. Scheidegger, A. Wittmer, and J. C. M. Andersson, "Understanding consumption-related sucralose emissions-A conceptual approach combining substance-flow analysis with sampling analysis," Science of the Total Environment, vol. 408, pp. 3261-3269, 2010.

[7] R. N. Mead, J. B. Morgan, G. B. Avery, R. J. Kieber, A. M. Kirk, S. A. Skrabal, and J. D. Willey, "Occurrence of the artificial sweetener sucralose in coastal and marine waters of the United States," Marine Chemistry, vol. 116, pp. 13-17, 2009

[8] K. E. Tollefsen, L. Nizzetto, and D. B. Huggett, "Presence, fate and effects of the intense sweetener sucralose in the aquatic environment," Science of the Total Environment, vol. 438, pp. 510-516, 2012.

[9] Alternative Disinfectants and Oxidants Guidance Manual, USEPA Standard EPA 815-R-99-014-1999.

[10] J. R. Guimarães, M. C. Gasparini, M. G. Maniero, and C. G. N. Mendes, "Stripped sour water treatment by advanced oxidation processes," J. Braz. Chem. Soc., vol. 23, no. 9, pp. 1680-1687, 2012.

[11] C. P. Huang, C. Dong, and Z. Tang, "Advanced chemical oxidation: its present role and potential future hazardous waste treatment," Waste Management, vol. 13, pp. 361-377, 1993.

[12] O. Legrini, E. Oliveros, and A. M. Braun, "Photochemical processes for water treatment," Chem. Rev., vol. 93, pp. 671-698,1993.

[13] T. A. Albanis, F. D. Bello, A. D. Vlachou, and C. Medana, V. A. Sakkas, and P. Calza, "Chemometric assesment and investigation of mechanism involved in photo-Fenton and $\mathrm{TiO}_{2}$ photocatalytic degradation of the artificial sweetener sucralose in aqueous media," Applied Catalysis B: Environmental, vol. 129, pp. 71-79, 2013.

[14] K. G. Linden and O. S. Keen, "Re-engineering an artificial sweetener: transforming sucralose residuals in water via advanced oxidation," Environmental Science \& Technology, vol. 47, pp. 6799-6805, 2013.

[15] C. I. Torres, S. Ramakrishna, C. A Chiu, K. G. Nelson, P. Wasterhoff, and R. K. Brown, "Fate of sucralose during wastewater treatment," Environmental Engineering Science, vol. 8, no. 5, pp. 325-331, 2011.

[16] A. Zygler, A. Wasik, A. Kot-Wasik, and J. Namiesnik, "Determination of nine high-intensity sweeteners in various foods by high-performance liquid chromatography with mass spectrometric detection," Analytical and Bioanalytical Chemistry, vol. 400, no. 7, pp. 2159-2172, 2011.

[17] M. C. Oliveira, R. F. P. Nogueira, J. A. G. Neto, W. F. Jardim, and J. J. R. Rohwedder, "Sistema de injeção em fluxo espectrofotométrico para monitorar peróxido de hidrogênio residual em processo de fotodegradação por reação foto-Fenton," Química Nova, vol. 24, pp. 188-190, 2001.

[18] Toxicity Test with Vibrio Fischeri Luminescent Bacteria: Assay Method, CETESB Standard L5.227-2001.

[19] J. R. Guimarães, M. G. Maniero, and R. N. de Araujo, “A comparative study on the degradation of RB-19 dye in an aqueous médium by advanced oxidation processes," Journal of Environmental Management, vol. 110, pp. 33-39, 2012.

[20] C. R. Silva, M. G. Maniero, S. Rath, and J. R. Guimarães, "Degradation of flumequine by the fenton and photo-fenton processes: evaluation of residual antimicrobial activity," Science of the Total Environment, vol. 445-446, pp. 337-346, 2013.

[21] J. R. Guimarães, C. R. T. Farah, M. G. Maniero, and P. S. Fadini, "Degradation of formaldehyde by advanced oxidation processes," Journal of Environmental Management, vol. 107, pp. 96-101, 2012.

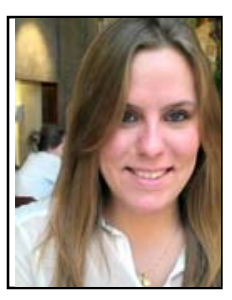

Gabriela Filipini Ferreira is an undergraduate student at Chemical Engineering School of University of Campinas. She was born in Campinas, Brazil, on 1992.

She developed her scientific research (scholarship from $\mathrm{CNPq} / \mathrm{PIBIC})$ at the School of Civil Engineering, Architecture and Urban Design of Unicamp, Campinas, Brazil, at Department of Sanitation and Environment; she worked with sweetener's degradation by advanced oxidation processes. On September, 2014, she is going to the University of Manchester, in United Kingdom (year exchange program), with scholarship from the Science without Borders program. 


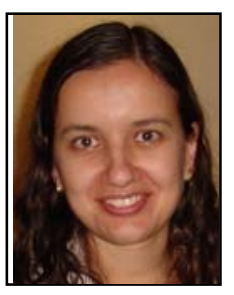

Milena Guedes Maniero was graduated in chemical engineering from Federal University of São Carlos in 2000, she received her masters in chemical engineering from Federal University of São Carlos in 2003 and Ph.D. in chemical engineering from Federal University of Rio de Janeiro in 2008 she was born in Tupã, São Paulo, Brazil, on 1978.

She has published 14 papers, one book chapter, and 40 abstracts and full papers in congress. Currently, she is a collaboratingres earcherat the School of Civil Engineering, Architecture and Urban Design of Unicamp, Campinas, Brazil, at Department of Sanitation and Environment. She has experience in water pollution control, especially in the treatment of micropollutants (estrogens and pharmaceuticals) by ozonation and advanced oxidation processes.

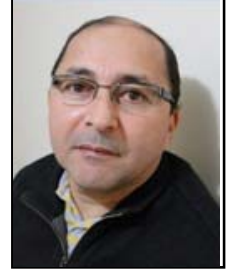

José Roberto Guimarães was graduated in chemistry by University of Campinas, he received his master in chemistry from University of Campinas and doctor in chemistry from University of Campinas. He was born in Adamantina, São Paulo, Brazil.

He has published 44 papers, 2 books, one book chapter, and 165 abstracts and full papers in congress. He is a titular professor at School of Civil Engineering, Architecture and Urban Design of Unicamp, Campinas, Brazil, at Department of Sanitation and Environment. Nowadays, he is a coordinator of the post-graduate program of Civil Engineering (FEC-UNICAMP). He has experience in sanitation and environmental chemistry. He works with advanced oxidation processes for degradation of recalcitrant molecules, veterinary drugs, potentially toxic effluents, and inactivation of emerging and re-emerging microorganisms. 